\title{
BMJ Open Adolescents' physical activity trends over the years: a three-cohort study based on the Health Behaviour in School-aged Children (HBSC) Portuguese survey
}

\author{
Adilson Marques, ${ }^{1,2}$ Margarida Gaspar de Matos $^{2,3}$
}

To cite: Marques A, Gaspar de Matos M. Adolescents' physical activity trends over the years: a three-cohort study based on the Health Behaviour in School-aged Children (HBSC) Portuguese survey. BMJ Open 2014;4: e006012. doi:10.1136/ bmjopen-2014-006012

- Prepublication history for this paper is available online. To view these files please visit the journal online (http://dx.doi.org/10.1136/ bmjopen-2014-006012).

Received 1 July 2014 Revised 28 July 2014 Accepted 21 August 2014

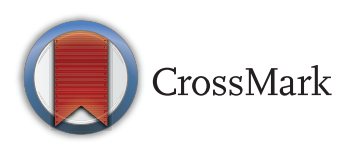

${ }^{1}$ Projeto Aventura Social, Lisboa, Portugal ${ }^{2}$ Centro Interdisciplinar de Estudo da Performance Humana, Faculdade de Motricidade Humana, Universidade de Lisboa, Lisboa, Portugal

${ }^{3}$ Centro de Malária e Outras Doenças Tropicais (CMDT), Universidade Nova de Lisboa, Lisboa, Portugal

Correspondence to Dr Adilson Marques; amarques@fmh.ulisboa.pt

\section{ABSTRACT}

Objective: Many young people do not practise enough physical activity (PA) to benefit their health. The three-cohort study aimed to investigate the prevalence of $\mathrm{PA}$ and understand the trends between 2002 and 2010, using a representative sample of Portuguese adolescents.

Design, setting and participants: The participants were 8483 adolescents (4067 boys, 4416 girls) who participated in the Health Behaviour in School-aged Children Portuguese survey in 2002, 2006 and 2010.

Design, setting and participants: A questionnaire was used to collect data of PA. Analyses were run separately for boys and girls.

Results: Boys aged 15-17 reported practising 3.5 \pm 1.9 times a week in 2002, 3.9 \pm 1.9 times a week in 2006 and $3.8 \pm 1.9$ times a week in 2010, with a significant increase from 2002 to 2006/2010 $(p<0.05)$. PA practice during the past 7 days decreased from $4.2 \pm 2.1$ to $3.9+1.9$ between 2002 and $2006(p<0.001)$ and also decreased from $4.4 \pm 2.1$ to $3.8 \pm 1.9$ between 2006 and $2010(p<0.001)$. Among girls, PA practices during the past 7 days declined significantly from $3.5 \pm 1.9$ to $2.7 \pm 1.7$ between 2002 and $2006(p<0.001)$, and from $3.3 \pm 1.9$ to $2.9 \pm 1.7$ between 2006 and $2010(p<0.001)$. Conclusions: The study points to age as a factor related to diminished PA participation. The study also revealed that the prevalence of PA has decreased over the years for the same age groups.

\section{INTRODUCTION}

Young people's participation in physical activity (PA) is associated with health benefits, specifically improved bone mineral density, aerobic fitness, muscular strength, endurance, cardiovascular risk factors and mental health. ${ }^{1}$ There is also a negative relationship between PA and careless nutrition, overweight and obesity among young people. ${ }^{2}{ }^{3}$ Additionally, PA incorporated as a personal habit at a young

\section{Strengths and limitations of this study}

- Data from a representative sample were collected from three different cohorts (2002, 2006 and 2010), using a standard protocol, which allows for comparisons and for an understanding of the differences of physical activity (PA) over the years in two different age groups of boys and girls.

- Measurements of PA were based on self-report. Self-report generally has limited reliability and validity. So the use of accurate objective measures is preferable, but it is not often feasible in epidemiological studies with large samples.

- Boys and girls do not practise enough PA to meet the recommended levels of $60 \mathrm{~min}$ in moderate to vigorous intensity on all or most days of the week. From a public health perspective, there is a need to augment the time spent on PA.

- Soccer is the most practised sports activity among boys and older girls. Thus, when considering an intervention aimed at increasing PA, soccer should be considered as an activity that attracts adolescents.

age may persist into adulthood. ${ }^{4}$ Thus, current guidelines from the WHO recommend that young people should engage in at least $60 \mathrm{~min}$ of PA in moderate to vigorous intensity on all or most days of the week. ${ }^{5}$

In spite of the health benefits, data suggest that many young people are not engaging in PA of sufficient length and intensity to benefit their health. ${ }^{6} 7$ The Portuguese figures are quite dramatic, revealing that only $36 \%$ of children aged $10-11$ and $4 \%$ of adolescents aged 16-17 were considered sufficiently active. ${ }^{8}$ Besides the lower levels of $\mathrm{PA}$, the prevalence of active children and adolescents tended to decrease with age, particularly among girls.

In order to intervene and reverse this situation, it is important to understand the trends 
of PA over the years as well as the PA practices of adolescents. Nonetheless, since most adolescents do not commute actively to school, do not spend much time on PA and spend excessive time in sedentary behaviours, ${ }^{9}$ it is important to highlight sport participation. Studies have shown that sport participation contributes to adolescent attained PA guidelines, ${ }^{10}$ and there is evidence that adolescents who participated in sports are more persistent exercisers than non-participants. ${ }^{11}$ Most studies related to PA and sports participation are cross-sectional ${ }^{8912}$ and results can only be interpreted in the light of the period in which they were collected. Since little is known about the PA and sport participation of adolescents and how they have evolved over the years, studies that allow researchers to compare patterns and practices of PA and sport participation are needed. Therefore, the present three-cohort study, using a representative sample of Portuguese adolescents, aimed to investigate the prevalence of PA and sport participation among Portuguese adolescents and understand how it has changed between 2002 and 2010.

\section{METHODS}

Participants

A proportionate nationally representative sample of 8483 adolescents (4067 boys, 4416 girls), randomly selected from grades 6 and 10, participated in the Health Behaviour in School-aged Children (HBSC) Portuguese survey in $2002 \quad(\mathrm{n}=3023), 2006 \quad(\mathrm{n}=2556)$ and 2010 $(\mathrm{n}=2904) .{ }^{13-15}$ HBSC Portugal is one of 43 countries and regions across Europe and North America that make up the HBSC Network. HBSC collects data every 4 years on children's and adolescents' health and well-being, social environments and health behaviours. Data are used at a national and international level to add new vision into young people's health and well-being, understand the social and psychological determinants of health, and incorporate policies to improve young people's lives. The methodological aspects of the HBSC study are well developed and published internationally. ${ }^{16}$ The study received approval from the Ethical Committee of Porto Medical School and the Portuguese National Data Protection System. All school administrators gave their consent, legal guardians gave written informed consent, and students provided assent.

\section{Measures}

For data collection, a questionnaire was used that was designed by the international HBSC members and is described in detail elsewhere. ${ }^{16} 17$ To assess PA, adolescents were provided with a common definition of PA, ${ }^{18}$ and then were asked 'How many days did you practice PA during the past 7 days?' Answers were given on an 8-point scale $(1=$ none to $8=$ daily). Seven days of PA recall is shown to be reliable and valid for use in research on PA in adolescents. ${ }^{19}$ Adolescents were also asked if they practised regular PA during the past 6 months. Answers were yes ( $\geq 3$ times a weeks) or no $(<3$ times a week). The item has a high reliability, with intraclass correlation coefficients ( 1 week interval) of 0.95 . Adolescents were then asked about the sports activity they usually practised in organised or non-organised contexts.

\section{Procedures}

Questionnaires were administered in schools in January 2002, 2006 and 2010, and were answered anonymously. Participation in the study was voluntary. The administration of the surveys was conducted according to standard guidelines from the HBSC survey protocol,,${ }^{16}$ and it was carried out by trained schoolteachers during class time.

\section{Analysis}

Adolescents were grouped into two age groups (11-13 and 15-17). Descriptive statistics were calculated for all variables (means, SD and percentages) for the entire sample and according to HBSC survey years (2002, 2006 and 2010), age group and sex. Analysis of variance and $\chi^{2}$ test were used to assess the differences among HBSC survey years in each age group. Independent $t$ tests and $\chi^{2}$ were used to compare adolescents from different cohorts. All statistical analyses were performed using IBM SPSS Statistics V.20.0. The level of significance was set at 0.05 .

\section{RESULTS}

Sample characteristics are displayed in table 1.

Descriptive statistics and the differences among HBSC survey years for each age group and sex are presented in table 2.

For boys aged 11-13, the number of times they reported practising PA during the past 7 days was between $4.2 \pm 2.1$ to $4.4 \pm 2.1$ times. At the age of $15-17$, they reported practising $3.5 \pm 1.9$ times a week in 2002, $3.9 \pm 1.9$ times a week in 2006 and $3.8 \pm 1.9$ times a week in 2010, with a significant increase from 2002 to 2006/2010 $(p<0.05)$. In both age groups, the prevalence of PA over the past 6 months decreased slightly between 2006 and 2010, but decreased significantly between 2006 and 2010 $(p<0.05$ and $p<0.01)$. Soccer was the most practised sports activity, but over the years there was a significant decline in the number of participants $(p<0.001$ for both age-groups). On the other hand, gymnastics participation decreased from 2002 to 2006 and then increased from 2006 to 2010, reaching the higher value in 2010 for the ages of 11-13 $(\mathrm{p}<0.05)$ and $15-17$ years $(p<0.05)$. The type of PA practised changed over the years for the younger participants, showing a decrease in the number of team sports participants and an increase in those participating in individual sports $(\mathrm{p}<0.01)$. Boys, younger and older, preferred team sports activities more than individual activities. However, over the years, the number of young boys participating in team sports decreased progressively from 2002 to $2010(p<0.01)$.

Girls reported practising PA between $3.3 \pm 1.9$ to $3.5 \pm 1.9$ times a week at the age of $11-13$, and $2.7 \pm 1.9$ to 
Table 1 Characteristics of participants

\begin{tabular}{|c|c|c|c|c|c|c|c|c|}
\hline & \multicolumn{2}{|l|}{ Total } & \multicolumn{2}{|l|}{2002} & \multicolumn{2}{|c|}{$\begin{array}{l}\text { Cohorts } \\
2006\end{array}$} & \multicolumn{2}{|l|}{2010} \\
\hline & $\mathbf{n}$ & Per cent & $\mathbf{n}$ & Per cent & $\mathbf{n}$ & Per cent & $\mathbf{n}$ & Per cent \\
\hline \multicolumn{9}{|l|}{ Sex } \\
\hline Boys & 4067 & 47.9 & 1466 & 48.5 & 1261 & 49.3 & 1340 & 46.1 \\
\hline Girls & 4416 & 52.1 & 1557 & 51.5 & 1298 & 50.7 & 1561 & 53.9 \\
\hline \multicolumn{9}{|l|}{ Age } \\
\hline $11-13$ & 4266 & 50.3 & 1746 & 57.8 & 1275 & 49.8 & 1245 & 42.9 \\
\hline $15-17$ & 4217 & 49.7 & 1277 & 42.2 & 1284 & 50.2 & 1656 & 57.1 \\
\hline \multicolumn{9}{|l|}{ School grade } \\
\hline Sixth grade & 4348 & 51.3 & 1809 & 59.8 & 1275 & 49.8 & 1264 & 43.5 \\
\hline Tenth grade & 4135 & 48.7 & 1214 & 40.2 & 1284 & 50.2 & 1637 & 56.5 \\
\hline
\end{tabular}

$2.9 \pm 1.7$ times a week at the age of $15-17$. Soccer, gymnastics and swimming were the most popular sports activities. Over the years, the number of soccer practitioners decreased significantly among younger girls $(p<0.001)$. For the older girls, the number of participants decreased significantly from 2002 to 2006, and then increased significantly from 2006 to $2010(\mathrm{p}<0.001)$. In respect of gymnastics, the number of participants decreased significantly from 2002 to 2006/2010 for both younger $(p<0.01)$ and older girls $(p<0.01)$. The number of older girls that practised volleyball was inconsistent, decreasing significantly from 2002 to 2006 and increasing significantly from 2006 to $2010(\mathrm{p}<0.05)$. Girls aged 11-13 preferred individual sports activities rather than team sports activities over the years $(\mathrm{p}<0.05)$. On the other hand, among older girls, the number of participants in individual sports activities decreased significantly from 2006 to $2010(\mathrm{p}<0.01)$.

Table 3 presents PA information from 2 different cohorts, 4 years apart. Among boys, PA practices during the past 7 days decreased from $4.2 \pm 2.1$ to $3.9 \pm .1 .9$ between 2002 and $2006(\mathrm{p}<0.001)$, and again decreased from 4.4 \pm 2.1 to $3.8 \pm 1.9$ between 2006 and 2010 $(\mathrm{p}<0.001)$. The prevalence of PA practised over the past 6 months also declined significantly in both cohorts $(\mathrm{p}<0.001)$. Looking at the different sports activities, the number of practitioners decreased over the years in almost all activities. It is noteworthy that only volleyball from 2002 to 2006 and swimming from 2006 to 2010 remained relatively stable. In both cohorts, as age increased, the number of participants in team sports activities declined, and, in contrast, the number of participants in individual activities increased significantly $(\mathrm{p}<0.001)$.

Among girls, PA practices during the past 7 days declined significantly from $3.5 \pm 1.9$ to $2.7 \pm 1.7$ between 2002 and $2006(\mathrm{p}<0.001)$, and from $3.3 \pm 1.9$ to $2.9 \pm 1.7$ between 2006 and $2010(\mathrm{p}<0.001)$. Similar to what was observed among boys, the prevalence of PA over the past 6 months decreased in both cohorts $(p<0.001)$. The practice of PA decreased significantly in all sports activities from 2002 to 2006. Data from 2006 and 2010 show that the practice of PA also declined, with the exception of handball, which remained stable, and volleyball, which in contrast to other sports had a marginally significant increase $(p=0.052)$. Girls team and individual sports participation decreased between 2002 and 2006 $(\mathrm{p}<0.001)$ and between 2006 and $2010(\mathrm{p}<0.01)$.

\section{DISCUSSION}

This is the first study among Portuguese adolescents to explore the PA and sport participation of different cohorts, collecting data through the same standard protocol. The goal of the three-cohort study was, using a representative sample of Portuguese adolescents, to investigate the prevalence of PA and sport participation among Portuguese adolescents, and understand how it changed between 2002 and 2010. Overall, the study points to age as a factor related to diminished PA participation. The study also revealed that the prevalence of PA and sport participation has decreased over the years for the same age groups.

Younger and older adolescents reported practising PA less than seven times a week. Although the duration and intensity of PA were not assessed, results indicated that adolescents do not get enough practice to meet the recommended levels of $60 \mathrm{~min}$ of moderate to vigorous PA each day. ${ }^{5}$ This is in line with other recent studies among Portuguese people that described the prevalence of PA. ${ }^{12}$ Since our data are from different HBSC waves, it was possible to observe the evolution of PA in each age group over the 2002-2010 time frames. With the exception of boys aged 15-17, there were no significant changes over the years in regard to PA practised during the past 7 days. Moreover, there was a decrease in the prevalence of PA over the past 6 months, especially among boys. These results can be interpreted in several different ways. First, strategies to increase the number of times that adolescents practise PA have not been successful. Second, adolescents and adults may not be aware of the recommended levels of PA for young people. Consequently, they might assume that they are active enough and therefore may conclude that there is no 
Table 2 Boys' and girls' physical activity participation in 2002, 2006 and 2010, according to age group

\begin{tabular}{|c|c|c|c|c|c|c|c|c|}
\hline \multirow[b]{2}{*}{ Boys } & \multicolumn{4}{|c|}{$11-13$ years } & \multicolumn{4}{|c|}{$15-17$ years } \\
\hline & $\begin{array}{l}2002 \\
(n=865)\end{array}$ & $\begin{array}{l}2006 \\
(n=686)\end{array}$ & $\begin{array}{l}2010 \\
(n=625)\end{array}$ & p Value & $\begin{array}{l}2002 \\
(n=601)\end{array}$ & $\begin{array}{l}2006 \\
(n=575)\end{array}$ & $\begin{array}{l}2010 \\
(n=715)\end{array}$ & p Value \\
\hline $\mathrm{PA}$ in the past 7 days $(\mathrm{M} \pm \mathrm{SD})^{*}$ & $4.2 \pm 2.1$ & $4.4 \pm 2.1$ & $4.3 \pm 2.1$ & 0.243 & $3.5 \pm 1.9$ & $3.9 \pm 1.9$ & $3.8 \pm 1.9$ & $0.019 \dagger$ \\
\hline PA in the past 6 months $(\%) \ddagger$ & & & & 0.012 & & & & 0.001 \\
\hline Did not practise PA & 5.4 & 5.5 & 9.0 & & 11.1 & 12.9 & 18.0 & \\
\hline Practised PA & 94.6 & 94.5 & 91.0 & & 88.9 & 87.1 & 82.0 & \\
\hline \multicolumn{9}{|l|}{ Sports practised (\%)‡ } \\
\hline Soccer & 72.6 & 69.8 & 60.8 & $<0.001$ & 57.1 & 50.1 & 44.3 & $<0.001$ \\
\hline Basketball & 22.1 & 26.4 & 22.4 & 0.102 & 16.6 & 12.7 & 13.7 & 0.130 \\
\hline Volleyball & 8.6 & 12.4 & 10.6 & 0.089 & 9.2 & 7.8 & 8.1 & 0.683 \\
\hline Handball & 9.7 & 11.8 & 11.2 & 0.388 & 8.3 & 7.1 & 7.0 & 0.619 \\
\hline Swimming & 18.0 & 15.3 & 17.3 & 0.352 & 15.8 & 13.6 & 15.5 & 0.500 \\
\hline Athletics & 12.7 & 13.8 & 13.1 & 0.806 & 8.2 & 7.7 & 9.2 & 0.575 \\
\hline Gymnastics & 17.5 & 17.1 & 22.2 & 0.027 & 7.0 & 3.8 & 6.7 & 0.038 \\
\hline Cycling & 22.7 & 24.2 & 21.4 & 0.490 & 18.5 & 16.7 & 14.7 & 0.181 \\
\hline Type of sport activity $\ddagger$ & & & & 0.008 & & & & 0.524 \\
\hline Individual & 8.7 & 8.3 & 13.0 & & 13.3 & 13.6 & 13.4 & \\
\hline Team & 40.9 & 38.2 & 33.8 & & 41.3 & 38.4 & 33.0 & \\
\hline Individual and collective & 38.5 & 37.8 & 34.9 & & 24.6 & 19.7 & 19.7 & \\
\hline Girls & $2002(n=881)$ & $2006(n=589)$ & $2010(n=620)$ & p Value & $2002(n=676)$ & $2006(n=709)$ & $2010(n=944)$ & p Value \\
\hline $\mathrm{PA}$ in the past 7 days $(\mathrm{M} \pm \mathrm{SD})^{*}$ & $3.5 \pm 1.9$ & $3.3 \pm 1.9$ & $3.4 \pm 1.9$ & 0.456 & $2.7 \pm 1.9$ & $2.7 \pm 1.7$ & $2.9 \pm 1.7$ & 0.056 \\
\hline PA in the past 6 months $(\%) \ddagger$ & & & & 0.491 & & & & 0.745 \\
\hline Did not practise PA & 15.7 & 13.4 & 14.8 & & 31.8 & 30.7 & 32.5 & \\
\hline Practised PA & 84.3 & 86.6 & 85.2 & & 68.2 & 69.3 & 67.5 & \\
\hline \multicolumn{9}{|l|}{ Sports practised (\%)‡ } \\
\hline Soccer & 35.3 & 31.4 & 25.8 & $<0.001$ & 15.7 & 9.7 & 16.7 & $<0.001$ \\
\hline Basketball & 17.8 & 16.6 & 18.7 & 0.640 & 9.3 & 7.2 & 9.6 & 0.189 \\
\hline Volleyball & 14.0 & 11.0 & 10.3 & 0.069 & 13.6 & 9.7 & 14.5 & 0.012 \\
\hline Handball & 6.1 & 6.3 & 8.4 & 0.191 & 2.7 & 3.8 & 5.8 & 0.006 \\
\hline Swimming & 25.0 & 21.2 & 21.0 & 0.112 & 13.5 & 14.8 & 13.9 & 0.757 \\
\hline Athletics & 12.4 & 11.0 & 13.7 & 0.370 & 5.8 & 5.4 & 7.5 & 0.155 \\
\hline Gymnastics & 36.1 & 28.4 & 29.4 & 0.002 & 15.4 & 10.4 & 9.5 & 0.001 \\
\hline Cycling & 12.8 & 10.7 & 10.0 & 0.195 & 6.2 & 6.1 & 6.1 & 0.993 \\
\hline Type of sport activity $\ddagger$ & & & & 0.015 & & & & 0.002 \\
\hline Individual & 28.0 & 26.8 & 28.4 & & 21.2 & 21.6 & 16.3 & \\
\hline Team & 17.0 & 21.1 & 14.7 & & 19.2 & 13.7 & 18.8 & \\
\hline Individual and collective & 30.0 & 23.2 & 25.0 & & 11.4 & 8.5 & 12.0 & \\
\hline
\end{tabular}

${ }^{*}$ Tested by analysis of variance.

†Data from 2002 are statically different from data for 2006 and 2010. Tested by Tukey's honest significant difference.

$\ddagger$ Tested by $\chi^{2}$ test.

PA, physical activity. 
Table 3 Boys' and girls' physical activity participation over the years

\begin{tabular}{|c|c|c|c|c|c|c|}
\hline Boys & $\begin{array}{l}2002 \\
11-13 \text { years } \\
(n=865)\end{array}$ & $\begin{array}{l}2006 \\
15-17 \text { years } \\
(n=575)\end{array}$ & p Value & $\begin{array}{l}2006 \\
11-13 \text { years } \\
(n=686)\end{array}$ & $\begin{array}{l}2010 \\
15-17 \text { years } \\
(n=715)\end{array}$ & p Value \\
\hline$P A$ in the past 7 days $\left(M \pm S D^{*}\right.$ & $4.2 \pm 2.1$ & $3.9 \pm 1.9$ & 0.001 & $4.4 \pm 2.1$ & $3.8 \pm 1.9$ & $<0.001$ \\
\hline PA in the past 6 months (\%)† & & & $<0.001$ & & & $<0.001$ \\
\hline Did not practise PA & 5.4 & 12.6 & & 5.5 & 18.0 & \\
\hline Practised PA & 94.6 & 87.4 & & 94.5 & 82.0 & \\
\hline \multicolumn{7}{|l|}{ Sports practised (\%)† } \\
\hline Soccer & 72.6 & 51.1 & $<0.001$ & 69.8 & 45.1 & $<0.001$ \\
\hline Basketball & 22.1 & 13.9 & $<0.001$ & 26.4 & 14.0 & $<0.001$ \\
\hline Volleyball & 8.6 & 8.6 & 0.082 & 12.4 & 9.1 & 0.010 \\
\hline Handball & 9.7 & 6.9 & 0.104 & 11.8 & 7.2 & 0.002 \\
\hline Swimming & 18.0 & 13.6 & 0.029 & 15.3 & 15.2 & 0.941 \\
\hline Athletics & 12.7 & 7.8 & 0.002 & 13.8 & 9.3 & 0.007 \\
\hline Gymnastics & 17.5 & 4.7 & $<0.001$ & 17.1 & 7.1 & $<0.001$ \\
\hline Cycling & 22.7 & 17.0 & 0.006 & 24.2 & 14.8 & $<0.001$ \\
\hline Type of sport activity $†$ & & & $<0.001$ & & & $<0.001$ \\
\hline Individual & 8.7 & 13.6 & & 8.3 & 13.4 & \\
\hline Team & 40.9 & 38.4 & & 38.2 & 33.0 & \\
\hline Individual and collective & 38.5 & 19.7 & & 37.8 & 19.7 & \\
\hline Girls & $\begin{array}{l}2002 \\
11-13 \text { years } \\
(n=881)\end{array}$ & $\begin{array}{l}2006 \\
15-17 \text { years } \\
(n=709)\end{array}$ & p Value & $\begin{array}{l}2006 \\
11-13 \text { years } \\
(n=589)\end{array}$ & $\begin{array}{l}2010 \\
15-17 \text { years } \\
(n=944)\end{array}$ & p Value \\
\hline $\mathrm{PA}$ in the past 7 days $(\mathrm{M} \pm \mathrm{SD})^{*}$ & $3.5 \pm 1.9$ & $2.7 \pm 1.7$ & $<0.001$ & $3.3 \pm 1.9$ & $2.9 \pm 1.7$ & $<0.001$ \\
\hline PA in the past 6 months $(\%) \dagger$ & & & $<0.001$ & & & $<0.001$ \\
\hline Did not practise PA & 15.7 & 30.1 & & 13.4 & 32.1 & \\
\hline Practised PA & 84.3 & 69.9 & & 86.6 & 67.9 & \\
\hline \multicolumn{7}{|l|}{ Sports practised $(\%) \dagger$} \\
\hline Soccer & 35.3 & 11.1 & $<0.001$ & 31.4 & 16.6 & $<0.001$ \\
\hline Basketball & 17.8 & 7.5 & $<0.001$ & 16.6 & 9.7 & $<0.001$ \\
\hline Volleyball & 14.0 & 10.0 & 0.011 & 11.0 & 14.5 & 0.052 \\
\hline Handball & 6.1 & 3.7 & 0.039 & 6.3 & 5.9 & 0.741 \\
\hline Swimming & 25.0 & 14.8 & $<0.001$ & 21.2 & 13.7 & $<0.001$ \\
\hline Athletics & 12.4 & 5.2 & $<0.001$ & 11.0 & 7.4 & 0.021 \\
\hline Gymnastics & 36.1 & 11.1 & $<0.001$ & 28.4 & 10.0 & $<0.001$ \\
\hline Cycling & 12.8 & 6.1 & $<0.001$ & 10.7 & 6.1 & 0.002 \\
\hline Type of sport activity $†$ & & & $<0.001$ & & & 0.004 \\
\hline Individual & 28.0 & 21.6 & & 26.8 & 16.3 & \\
\hline Team & 17.0 & 13.7 & & 21.1 & 18.8 & \\
\hline Individual and collective & 30.0 & 8.5 & & 23.2 & 12.0 & \\
\hline
\end{tabular}

need to be more physically active. ${ }^{20}$ Third, schools, even though called to give greater attention to provision of PA for students, ${ }^{21}$ seem to have failed at promoting PA. Results indicate that there has been no progress made towards attaining this goal.

Adolescent behaviour, such as PA and inactivity over the years, is an issue rarely studied in Portugal. This type of study is important and should be of interest at a national and international level because it helps policymakers, educators and health professionals to understand young people's health in their social context and tracks changes as they develop over the years. Therefore, with data from successive surveys, trends can be identified that make it possible to evaluate more accurately the impact of programmes and strategies implemented in order to promote PA and reduce sedentary behaviour among adolescents. While the HBSC conducts national $^{13-15}$ and international systematic surveys, ${ }^{6} 16$ in the USA, the Center for Disease Control and Prevention also conducts a periodic survey of adolescent health risk and health protective behaviours. ${ }^{22}$ This shows the importance of studying and tracking adolescent behaviour and allows cross-national comparisons.

The trend of PA declining with age was significant among boys and girls in the two different cohorts of adolescents (2002 to 2006 and 2006 to 2010). These results 
are similar to those found in other studies of adolescents from Portugal $^{23}$ and other countries. ${ }^{6}{ }^{7}$ In Europe, the inverse relationship between PA and age is common in most countries. ${ }^{6}$ In what is considered the first study to objectively measure physical activity with a representative sample of European children, Riddoch $e t a t^{4}$ verified that 9 -year-old children were considerably more active than 15-year-old adolescents, presenting similar results in all countries. Virtually all 9-year-old children practised the recommended amount of $\mathrm{PA}$, or more than recommended, while only a small percentage of 15-year-olds did so. This indicated that as age increased, PA decreased.

The decline of PA with age has triggered much discussion in the scientific community. Sallis ${ }^{25}$ analysed various studies related to the decline of PA, and concluded that the ages between 13 and 18 are at risk. Having also observed the decline in animals, the author was led to suppose that the decline had a biological origin. The consistency of the results of Riddoch et $a l^{24}$ among adolescents from different countries is in some way congruent with Sallis's ${ }^{25}$ assumptions, allowing one to conclude that children's and adolescents' PA is probably determined biologically. However, although the effect of age is significant on PA, it sometimes only explained $1 \%$ of the variability, ${ }^{26}$ which means that the decline in PA with age could be related to other factors such as the great academic pressure adolescents are under, ${ }^{27}$ longer time in sedentary activities such as screen time,${ }^{28}$ and having part-time jobs to earn some money. ${ }^{29}$ Therefore, qualitative studies to understand clearly the reasons for the decrease in PA among adolescents are needed.

Soccer was the most practised sports activity among boys and older girls over the years and at different ages. This is understandable since it is the most popular sports activity in Portugal, and it is the activity with the most participants. ${ }^{30}{ }^{31}$ Nevertheless, the number of participants decreased over the years within both age groups. As the number of participants in others sports activities did not increase significantly, this suggests that the decrease in soccer participants might be related to the prevalence of adolescents who did not practise PA over the past 6 months. This shows the importance of soccer as a sports activity among Portuguese adolescents. Thus, when considering an intervention aimed at increasing PA, soccer should be considered as an activity that attracts adolescents.

The type of activity practised by boys has the tendency to change over the years. While the number of team sports participants decreased between 11-13 and 15-17 years, participation in individual sports increased. On the other hand, for girls, participation in individual and team sports decreased with age. The reason for the choice of individual or team sports may be related to social factors, and some could argue that team sports would be better for the development of social skills. However, studies have shown that there is no difference in social self-esteem between participants in individual or team sports. ${ }^{32} 33$ For the older boys, the increased participation in individual sports may be related to their level of autonomy.

The present study has some limitations. Measurements of PA were based on self-report. Self-report generally has limited reliability and validity. ${ }^{34}$ So the use of accurate objective measures is preferable, but it is not often feasible in epidemiological studies with large samples. Moreover, the intensity and duration of PA were not measured. These evaluations would be useful in determining the prevalence of adolescents who attained the recommended levels of PA.

There are also several strengths in the present study. First, data from a representative sample were collected. Second, data from three different cohorts were collected (2002, 2006 and 2010), using a standard protocol, which allows for comparisons and for an understanding of the differences of PA over the years in two different age groups of boys and girls.

\section{CONCLUSION}

The prevalence of physical inactivity increased significantly among boys between ages 11-13 and 15-17, but not among girls. The number of times adolescents practised PA during the past 7 days remained relatively stable, which means that the campaigns and attempts to increase PA among adolescents have not been very successful. With age, there was a significant decrease in most sports activities among boys and girls. This indicated that as adolescents are getting older, they may have different interests leading some to stop practising PA. These findings imply that it is important to more effectively promote PA among adolescents, using different strategies based on age and sex.

Acknowledgements The authors thank the adolescents for their participation in the study. They also thank Joyce Voelker for revising the document.

Contributors AM and MGdM contributed to the conception and design. MGdM contributed to the acquisition of data. AM and MGdM contributed to the analysis and interpretation of the data. AM contributed to the drafting of the manuscript. AM and MGdM contributed to the revisions of the manuscript and the interpretation of the findings.

Funding The HBSC study in Portugal was funded by public funds: Ministry of Health and Ministry of Education and Science.

Competing interests None.

Patient consent Obtained.

Ethics approval Ethical Committee of Porto Medical School and the Portuguese National Data Protection System.

Provenance and peer review Not commissioned; externally peer reviewed.

Data sharing statement No additional data are available.

Open Access This is an Open Access article distributed in accordance with the Creative Commons Attribution Non Commercial (CC BY-NC 4.0) license, which permits others to distribute, remix, adapt, build upon this work noncommercially, and license their derivative works on different terms, provided the original work is properly cited and the use is non-commercial. See: http:// creativecommons.org/licenses/by-nc/4.0/ 


\section{REFERENCES}

1. Janssen I, Leblanc AG. Systematic review of the health benefits of physical activity and fitness in school-aged children and youth. Int $J$ Behav Nutr Phys Act 2010;7:40

2. Allender S, Kremer P, de Silva-Sanigorski A, et al. Associations between activity-related behaviours and standardized BMI among Australian adolescents. J Sci Med Sport 2011;14:512-21.

3. Santos MP, Oliveira J, Ribeiro JC, et al. Active travel to school, BMI and participation in organised and non-organised physical activity among Portuguese adolescents. Prev Med 2009;49:497-9.

4. Telama R, Yang X, Viikari J, et al. Physical activity from childhood to adulthood: a 21-year tracking study. Am J Prev Med 2005;28:267-73.

5. WHO. Global recommendations on physical activity for health. Genebra, Suiça: World Health Organization, 2010.

6. Currie C, Zanotti C, Morgan A, et al. Social determinants of health and well-being among young people. Health Behaviour in School-aged Children (HBSC) study: International Report From the 2009/2010 survey. Copenhagen: WHO Regional Office for Europe 2012.

7. Hallal PC, Andersen LB, Bull FC, et al. Global physical activity levels: surveillance progress, pitfalls, and prospects. Lancet 2012;380:247-57.

8. Baptista F, Santos DA, Silva AM, et al. Prevalence of the Portuguese population attaining sufficient physical activity. Med Sci Sports Exerc 2012;44:466-73.

9. Marques A, André J, Martins J, et al. The prevalence of sedentary behaviours and physical activity of urban adolescents. A crosssectional study using ecological momentary assessment. Mitt Klosterneuburg 2014;64:427-35.

10. Woods CB, Tannehill D, Quinlan A, et al. Children's sport participation and physical activity study (CSPPA). Dublin, Ireland: Dublin City University and Irish Sports Council, 2010.

11. Wichstrom L, von Soest T, Kvalem IL. Predictors of growth and decline in leisure time physical activity from adolescence to adulthood. Health Psychol 2013;32:775-84.

12. Marques A, Carreiro da Costa F. Levels of physical activity of urban adolescents according to age and gender. Int $J$ Sports Sci 2013;3:23-7.

13. Matos MG, Equipa do Projeto Aventura Social \& Saúde. A saúde dos adolescentes portugueses (Quatro anos depois) [The health of Portuguese adolescents (Four years later)]. Lisboa: Edições FMH, 2003.

14. Matos MG, Equipa do Projeto Aventura Social \& Saúde. A Saúde dos Adolescentes Portugueses-Hoje e em 8 anos-Relatório Preliminar do Estudo HBSC 2006 [The Portuguese Adolescent Health-Today and in eight years-Preliminary Report of the HBSC study in 2006]. Cruz Quebrada: Faculdade de Motricidade Humana, 2006.

15. Matos MG, Simões $\mathrm{C}$, Tomé $\mathrm{G}$, et al. Aventura social \& saúde. A saúde dos adolescentes portugueses. Relatório do estudo HBSC 2010 [Social adventure \& Health. The health of Portuguese adolescents. Report of the 2010 HBSC study]. Cruz-Quebrada: Faculdade de Motricidade Humana; 2011.

16. Currie $\mathrm{C}$, Hurrelmann $\mathrm{K}$, Settertobulte $\mathrm{W}$, et al. Health and health behavior among young people. Health behaviour in school-aged children: a WHO cross-national study (HBSC). Copenhagen: World Health Organization, 2000.
17. Currie C. Health behaviour in school-aged children. Research protocol for the 1997-98 survey. A world health organization cross-national study. Edinburgh University of Edinburgh, 1998.

18. Caspersen CJ, Powell KE, Christenson GM. Physical activity, exercise, and physical fitness: definitions and distinctions for health-related research. Public Health Rep 1985;

100:126-31.

19. Sallis JF, Buono MJ, Roby JJ, et al. Seven-day recall and other physical activity self-reports in children and adolescents. Med Sci Sports Exerc 1993;25:99-108.

20. Marques A, Martins J, Ramos M, et al. Perception and realityPortuguese adults' awareness of active lifestyle. Eur J Sport Sci 2013;14:468-74.

21. Pate RR, Davis MG, Robinson TN, et al. Promoting physical activity in children and youth: a leadership role for schools: a scientific statement from the American Heart Association Council on Nutrition, Physical Activity, and Metabolism (Physical Activity Committee) in collaboration with the Councils on Cardiovascular Disease in the Young and Cardiovascular Nursing. Circulation 2006;114: 1214-24.

22. Brener ND, Kann L, Shanklin S, et al. Methodology of the Youth Risk Behavior Surveillance System-2013. MMWR Recomm Rep 2013;62:1-20.

23. Seabra AFTE, Ribeiro Maia JA, Mendonca DM, et al. Age and sex differences in physical activity of Portuguese adolescents. Med Sci Sports Exerc 2008;40:65-70.

24. Riddoch CJ, Bo Andersen L, Wedderkopp N, et al. Physical activity levels and patterns of 9- and 15-yr-old European children. Med Sci Sports Exerc 2004;36:86-92.

25. Sallis JF. Age-related decline in physical activity: a synthesis of human and animal studies. Med Sci Sports Exerc 2000;32:1598-600.

26. Cantera-Garde M, Devís-Devís J. Physical activity levels of secondary school Spanish adolescents. Eur J Phys Educ 2000;5:28-44.

27. Lee KS, Trost SG. Physical activity patterns of Singaporean adolescents. Pediatr Exerc Sci 2006;18:400-14.

28. Sharif I, Sargent JD. Association between television, movie, and video game exposure and school performance. Pediatrics 2006;118: E1061-70.

29. Malina R, Bouchard C, Bar-Or O. Risk factors during growth and adult health. In: Malina R, Bouchard C, Bar-Or O, eds. Growth, maturation, and physical activity. Champaign: Human Kinetics, 2004:587-608.

30. Costa V, Serôdio-Fernandes A, Maia M. Hábitos desportivos dos jovens do interior norte e litoral norte de Portugal. Rev Port Ciênc Desporto 2009;9:46-55

31. Marivoet S. Hábitos desportivos da população portuguesa. Lisboa: Ministério da Juventude e do Desporto. Instituto Nacional de Formação e Estudos do Desporto, 2001

32. Dinc Z. Social self-efficacy of adolescents who participate in individual and team sports. Soc Behav Personal 2011;39:1417-23.

33. Wann DL, Lingle SE. Comparison of team and individual sports participants tendencies to join groups. Percept Motor Skill 1994;79:833-4.

34. Shephard RJ. Limits to the measurement of habitual physical activity by questionnaires. Brit J Sport Med 2003;37:197-206. 